\title{
A Suggested Relocation and Respacing of the Union Colorimeter Scale for Lubricating Oil and Petrolatum
}

\author{
By Deane B. Judd, Lorenzo Plaza, and Marion A. Belknap
}

\begin{abstract}
At the request of Research Division IX, Committee D-2 of the American Society for Testing Materials, a study of the chromaticities and daylight transmittances of petroleum products has been carried out. From the results of this study a recommended relocation of the ASTM Union colorimeter scale has been derived that is intended to minimize the difficulties frequently experienced in the color-grading of off-color petroleum products. This study also revealed in some detail discrepancies in color-grading between laboratories ascribable to failure of the glass color standards of the various Union colorimeters to conform to the master standards. It has been found possible to respace the color standards along the relocated locus by changes smaller than these interlaboratory discrepancies so as to yield uniform color steps as perceived by the eye under the conditions of observation prescribed by the method of test in ASTM D 155-45T. This relocation and respacing of the Union colorimeter scale is presented as a suggestion for possible adoption by the industry.
\end{abstract}

\section{Introduction}

Since 1923 it has been customary to measure and specify the color of lubricating oil and petrolatum by means of the ASTM Union colorimeter. ${ }^{1}$ This colorimeter consists of an artificial daylight assembly with flashed-opal diffuse light transmitter: a jar of internal diameter between 32.5 and 33.4 $\mathrm{mm}$ to hold the test sample; a series of 12 glass color standards ranging from pale greenish yellow to dark red and mounted in a vertical slide that may be raised or lowered to permit one or another of the standards to be viewed; a light shield to prevent extraneous light from falling on sample or standard; and an arrangement of partitions and diaphragms permitting the observer to view the color of the glass standard and the color of the test sample as filling two circles subtending at the eye of the observer about $2^{\circ}$ with their centers separated by about $6^{\circ}$, the surrounding field being dark. The glass color standards are combinations

1 ASTM Tentative method of tests for color of lubricating oil and petrolatum by means of ASTM colorimeter, ASTM Designation: D 155-45T, A STM standards, part III-A, p. 839 (1946). of Lovibond glasses obtained from Tintometer, Ltd.

The spectral transmittances of the master standards for the Union color scale were determined at this Bureau, ${ }^{2}$ and their luminous transmittances, $T_{0}$, and chromaticity coordinates, $x, y$, were computed in accord with the ICI standard observer and coordinate system for colorimetry ${ }^{3}$ by Scofield, Judd, and Hunter. ${ }^{4}$ Table 1 repeats the Lovibond analysis of these master standards given in $\mathrm{D} 155-45 \mathrm{~T}$ (see footnote 1), and gives the luminous transmittances and the chromaticity coordinates both on the ICI system $(x, y)$ and on the UCS system $(r, g) .^{5}$

\footnotetext{
2 Report of NBS Test No. 57968, issued December 18, 1929, to ASTM Committee D-2 on Petroleum Products and Lubricants.

3 Proceedings, Eighth Session, Commission Internationale de L'Éclairage, Cambridge, England, September 1931, p. 19-29; also A. C. Hardy, Handbook of colorimetry (Cambridge, Technology Press, 1936); also D. B. Judd, The 1931 ICI standard observer and coordinate system for colorimetry, J. Opt. Soc. Am. 23, 359 (1933).

4 F. Scofield, D. B. Judd, and R. S. Hunter, A proposed method of desig. nating color, ASTM Bulletin, p. 19 (May 1941).

D. B. Judd, A Maxwell triangle yielding uniform chromaticity scales, J. Research NBS 14, 41 (1935) RP756; J. Opt. Soc. Am. 25, 24 (1935).
} 
TABLE 1. Colorimetric specifications of the 12 glasses comprising the Union color scale; illuminant: ICI standard $C$ (average daylight)

\begin{tabular}{|c|c|c|c|c|c|c|c|c|}
\hline \multirow{2}{*}{$\begin{array}{c}\text { ASTM } \\
\text { color } \\
\text { num- } \\
\text { bers }\end{array}$} & \multicolumn{3}{|c|}{ Lovibond analysis } & \multirow{2}{*}{$\begin{array}{c}\text { Lumi- } \\
\text { nous } \\
\text { trans- } \\
\text { mit- } \\
\text { tance }\end{array}$} & \multicolumn{4}{|c|}{ Chromaticity coordinates } \\
\hline & Red & Yellow & Blue & & \multicolumn{2}{|c|}{ ICI system } & \multicolumn{2}{|c|}{ UCS system } \\
\hline 1. & 0.12 & 2.4 & & $\begin{array}{c}T_{0} \\
0.751\end{array}$ & $\begin{array}{c}x \\
0.3488\end{array}$ & $\begin{array}{c}y \\
0.3815\end{array}$ & $\begin{array}{c}r \\
0.462\end{array}$ & $\begin{array}{c}g \\
0.476\end{array}$ \\
\hline $11 / 2$ & .60 & 8.0 & & .654 & .3995 & .4460 & .491 & .477 \\
\hline 2 & 2.5 & 26.0 & & .443 & .4724 & .4765 & .542 & .448 \\
\hline $21 / 2$ & 4. 6 & 27.0 & & .365 & .4985 & .4570 & .570 & .421 \\
\hline $3 \ldots$ & 6. 9 & 32.0 & & .287 & .5252 & .4402 & .600 & .393 \\
\hline $31 / 2$ & 9.4 & 45.0 & & .211 & .5561 & .4234 & .636 & .360 \\
\hline $4 \ldots$ & 14.0 & 50.0 & 0.55 & .096 & .5908 & .3995 & .683 & .315 \\
\hline $41 / 2$ & 21.0 & 56.0 & .55 & .065 & .6199 & .3758 & .729 & .270 \\
\hline $5 \ldots$ & 35.0 & 93.0 & & .036 & .6528 & .3467 & .789 & .210 \\
\hline $6 \ldots$ & 60.0 & 60.0 & .55 & .017 & .6764 & .3234 & .841 & .159 \\
\hline 7. & 60.0 & 106. 0 & 1.8 & .0066 & .6841 & .3155 & .860 & .140 \\
\hline $8 \ldots$ & 166.0 & 64.0 & $\ldots$ & .0020 & .7140 & .2860 & .938 & .062 \\
\hline
\end{tabular}

To determine the ASTM color number of an oil, the oil is put into the standard jar, and the jar is placed in the right-hand compartment. In the other compartment is placed a 4-ounce sample bottle of distilled water. The jar and bottle are covered with the light shield, and the artificial daylight lamp is lighted. The color of the oil is obtained by determining the glass color standard that most nearly matches the color of the oil under examination. The colors of oils that are intermediate to the standard colors are expressed in terms of the darker as "lighter than" or "minus". For example, an oil that has a color between 7 and 8 is expressed as "lighter than 8 " or "8 minus". In determining the darker colors, the daylight lamp is sometimes moved closer to the opal-glass diffuser.

For many oils the Union colorimeter is quite satisfactory. The results are obtained rapidly, and one observer can repeat his own results or those of another observer without trouble. This indicates that the glass color standards have been chosen with some care so as to cover the color range of these oils with good precision. Other oils, however, depart considerably from the locus of colors defined by the 12 standards of the Union color scale. For such oils, the observer finds that none of the standards yields a color match, nor does it seem to him that the oil color is intermediate between any two of the standard colors.

\section{Committee Deliberations on Relocation}

Color is a three-dimensional quantity; it requires for its specification at least three independ- ent scales. The simplicity of the Union color scale is based upon the fact that it describes a one-dimensional variation. That is, the Union color scale corresponds to a single (curved) line in the color solid, and it serves well for those colors represented on (or near) that one line. Relocation of the one-dimensional color scale cannot make it applicable to all oils, but by choosing color standards that correspond to the average color of oils it is possible to minimize the difficulties introduced by off-color oils.

Another source of error in grading oils by ASTM Method D 155-45T arises from the difficulty of obtaining precise duplicates of the master standards of the Union color scale. At its Detroit meeting in June 1948, Subcommittee VI on Color, ASTM Committee D-2 on Petroleum Products, decided to cooperate with the C. J. Tagliabue Manufacturing Co., maker of the ASTM Union colorimeter, in an attempt to make possible the procurement of color standards from an American source of supply, procurement of satisfactorv duplicates from the present foreign source of supply (Tintometer, Ltd., Salisbury, England) having become increasingly difficult, due primarily to shortage in the supply of Lovibond glasses. It was proposed first that the master standards, or duplicates of certain of them that have become scratched or chipped, be submitted to the Corning Glass Works as a guide in the preparation of a set of glasses that should give a visual match for the colors of the master standards. Second, it was proposed that these matching color glasses be submitted to a referee laboratory, such as the Nationa! Bureau of Standards, so that their spectral transmittances might be determined and the luminous transmittances and chromaticity coordinates for illuminant $\mathrm{C}$ calculated. Third, it was suggested that tolerances in the procurement of duplicates from Corning Glass Works be set at \pm 0.006 in chromaticity coordinates $(r, g, b)$ on the UCS system and either at \pm 10 percent of the luminous transmittance or at 10 percent for the darker glasses with smaller tolerances on a sliding scale for the lighter glasses, the differences between the approved matching color glasses and the duplicates to be evaluated by visual colorimetry.

Following the Detroit meeting, a summary of available colorimetric data (transmittance and chromaticity coordinates on the UCS system) of 
the master standards and certain approximate duplicates of them prepared before 1939 by the Jena Glass Works of Germany was drawn up by H. M. Hancock, Chairman, and circulated on October 11, 1948, to the members of the subcommittee. This summary included remarks on the goodness of match judged by visual comparison of the Jena approximate duplicates with the respective master standards. This comparison corroborated the proposed tolerance on chromaticity coordinates $(r, g, b)$ of \pm 0.006 , and suggested that the transmittance tolerance be set at \pm 10 percent for the darkest glass (Union No. 8) and progressively reduced to about \pm 4 percent for the lightest (Union No. 1).

On November 5, 1948, a meeting of representatives of the C. J. Tagliabue Co., the Weston Electric Instrument Co., the Corning Glass Works, and Subcommittee VI, ASTM D-2, was held to discuss feasibility of procuring from Corning Glass Works duplicates of the master standards within these suggested tolerances. The representative of the Corning Glass Works (A. J. Werner) reported that the present glasses available through Corning would permit two-component combinations, one component being amethyst glass, to be made that would satisfy the tolerances above Union No. 31/2, but that those below $3 \frac{1}{2}$ exhibited a consistent shift toward yellow. A number of sets of these glasses have been made up and sold. Mr. Werner agreed to investigate the possibility of using a different combination of glasses that would satisfy the tolerances for glasses below $3 \frac{1}{2}$ also.

Following this preliminary meeting, the November 1948 meeting of Subcommittee VI was held in Chicago. It was pointed out in discussion of Mr. Werner's difficulty with glasses to duplicate the lighter standards (less than 31/2) that measurements of 22 petroleum products by Diller, De Gray, and Wilson ${ }^{6}$ indicated that they departed from the Union locus in the same range and direction. It was voted that the subcommittee undertake to determine the average colors of oils in the range of Union 1 to $3 \frac{1}{2}$ based upon a more adequate sampling than is afforded by the 22 products measured by Diller, De Gray, and Wilson. Accordingly, the various members of the subcommittee submitted representative samples of finished and

${ }^{6}$ I. M. Diller, R. J. De Gray, and J. W. Wilson, Jr., Photoelectric color, description, and mensuration of the color of petroleum products, lnd. Eng. Chem. 14, 607 (1942). processed petroleum products up to and including Union No. $3 \frac{1}{2}$ to H. M. Hancock, Chairman A selection of 49 representative samples of this group of petroleum products was then made, and the 49 samples were sent to this Bureau for measurement of luminous transmittance and chromaticity coordinates. One purpose of this paper is to give the method and results of these measurements and to recommend a relocation of the Union color scale based upon them.

\section{Committee Deliberations on Respacing}

At the Chicago meeting, the question of whether the present spacing of the color standards of the Union scale ought to be duplicated was also raised. It was pointed out that the scale proceeds by half steps up to 5 , then by whole steps up to 8. Furthermore, the perceptual difference between Union No. 6 and 7 is much smaller than that between 7 and 8 . This is shown by the spectrophotometric determinations (see table 1, $\left.r_{6}=0.841, r_{7}=0.860, r_{8}=0.938\right)$ and by visual inspection of the master standards. Would it not be better, it was argued, if we are going to relocate the Union locus anyway, to request Corning Glass Works to supply duplicates of a master set of standards having as close an approximation as is possible to uniform perceptual spacing? Is it not foolish to reproduce with great care all of the defects of a choice of color scale made in 1923 ? Some members of the subcommittee viewed with discomfort the prospect of changing the meaning of the various Union numbers. This would cause confusion between the old and the new meanings and would give rise to disputes and dislocations of present practice in writing purchase specifications of petroleum products, they thought. It was pointed out by $\mathrm{Mr}$. Hancock, however, that a great improvement in uniformity of spacing could be achieved by making changes that would be less than the spread between color standards of the same Union color number in the different colorimeters now in use. He presented two tentative suggestions, one at the meeting, one soon after, in a letter of November 24, 1948, showing that only relatively small changes might be required. Table 2 gives these tentative suggestions in terms of the $r$-coordinate of the UCS-system. 
TABLE 2. Suggestions by H. M. Hancock for respacing of the Union color scale

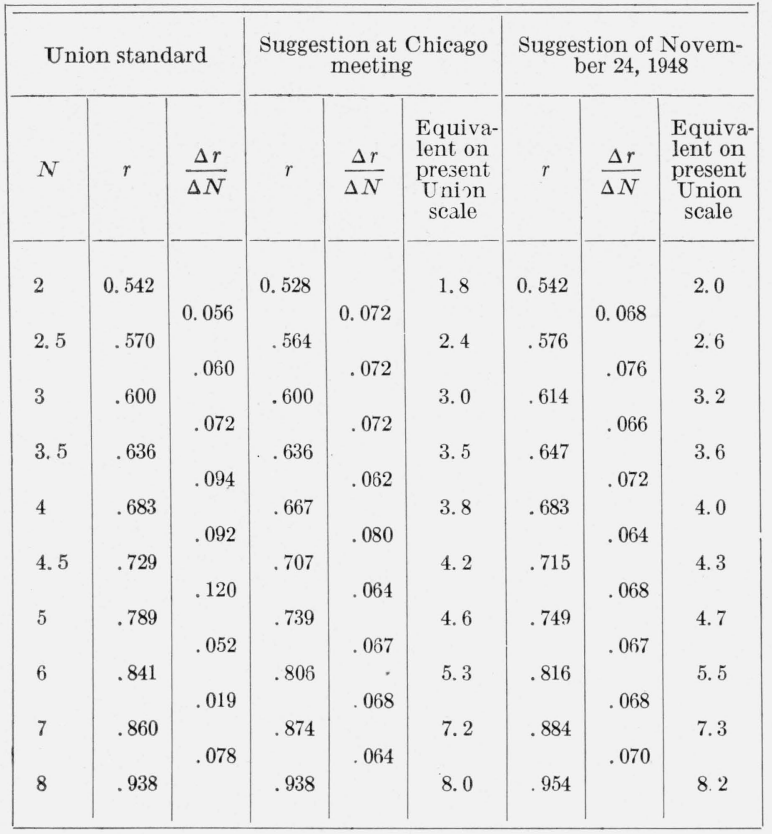

It may be seen from table 2 that the chromaticity spacing $((\Delta r / \Delta N)$ of the revisions suggested by $\mathrm{Mr}$. Hancock is indeed much more constant than that of the present Union scale. The variation in step size has been reduced from 0.100 in the Union scale to 0.018 in the Chicago suggestion and to 0.012 in the suggestion of November 24. These marked improvements in chromaticity spacing have been obtained by shifts that average about 0.2 of a step in the Union scale. In criticism of Mr. Hancock's suggestions, however, it was remarked at the Chicago meeting that the perceptual size of the steps in the color scale might not be correctly indicated by spacing of the $r$-coordinate of the colors. The UCS system gives a close approach to uniform chromaticity spacing only when the luminance of the fields being compared remains substantially at the same level. Since the luminous transmittance of the standards varies from 75 percent down to 0.2 percent, there is some question whether there is enough light available to permit the eye to distinguish the chromaticity differences between the darker members of the set of color standards with as much facility as those between the lighter members. Since the method permits moving the daylight lamp closer to the diffuser for the darker colors, it would seem that a lack of sufficient light is to be admitted and that some account should be taken of the luminance of the fields being compared by spacing out the darker members of the color scale more than would be indicated by a uniform spacing of chromaticity alone.

Another possibility that ought to be taken into account is the fact that the members of each pair of neighboring color standards in the set differ appreciably in luminous transmittance. Although the separation of the two fields to be compared by a sizable dark area tends to obscure the luminance difference between them, it is possible that the perceptual size of the step depends appreciably on the luminance difference as well as the chromaticity difference.

It was agreed at the Chicago meeting that suitable account should be taken of these two factors, and one of us (DBJ) was requested to derive a respacing of the Union scale that should appear uniform under the conditions of viewing embodied in the ASTM Union colorimeter. It is the second purpose of this paper to give the results of the derivation made.

\section{Measurement of Luminous Transmit- tance, $T$, and Chromaticity Coordinates, $x, y$, of 49 Samples of Petroleum Products}

Each of the 49 samples was compared by the substitution method with two glass standards of known spectral transmittance by means of a photoelectric colorimeter with tristimulus filters ${ }^{7}$ belonging to the Henry A. Gardner Laboratory, Bethesda, Md. This colorimeter is designed especially for the measurement of liquids in cylindrical cells and permitted one of us (MAB) to make the measurements of the samples without removing them from the sample bottles, which conform closely to the requirements of ASTM Method D 155-45T for the standard jar. Thanks are due to R. S. Hunter of the Henry A. Gardner Laboratory for his courtesy in permitting us to bring the oil samples to his laboratory for these measurements. The glass standards used are the master standards developed to check photoelectric colorimeters used to determine a color index for

\footnotetext{
7 R. S. Hunter, Photoelectric tristimulus colorimetry with three filters, NBS Circular C429 (July 30, 1942).
} 
petroleum products. $^{8}$ These glasses resemble petroleum products closely in spectral characteristics. The luminous transmittances of these glass standards for ICI illuminant C (average daylight) have been computed, together with the chromaticity coordinates $(x, y)$ by routine methods (see footnote 3 ). The reduction of the data to yield these quantities for the 49 samples of petroleum products was likewise carried out by routine methods (see footnote 7). From the agreement obtained between results by way of different standards it is estimated that the values of chromaticity coordinates $(x, y)$ are uncertain by not more than 0.005 . Table 3 shows the results; figure 1 is a portion of the $(x, y)$-chromaticity diagram showing how the chromaticity coordinates of these oils compare with the master standards of the Union color scale. The curve is the recommended relocation of the Union color scale; it is intended to be a smooth average of the chromaticity variation shown by the petroleum products. Note that with three exceptions all of the oil samples between Union 2 and 31/2 deviate from the Union locus in the direction of the spectrum locus. This corroborates the report by Diller, De Gray, and Wilson (see footnote 6), although these deviations average less than those for the petroleum products studied by them. It would appear from figure 1 that an appreciable reduction of trouble from off-color oils is to be obtained by this relocation of the Union color scale.

In addition to accomplishing their chief purpose of supplying information basic to relocation of the Union color scale, these data also constitute an interlaboratory comparison of grading by the ASTM Union colorimeter. This comes about from the fact that 46 out of the 49 oil samples were marked with the ASTM (or NPA) number when submitted. ${ }^{9}$ From figure 1 it is possible to estimate with a maximum uncertainty of 0.2 Union step what this number would be if the judgment had been made on the basis of nearest chromaticity. These estimates are given in the third column of table 1 . It is seen that on the average the ASTM number reported by the re-

8 A proposed method for determination of a color index for petroleum products, Appendix IV, 1947 Report of ASTM Committee D-2.

$\checkmark$ Acknowledgment is made to the following laboratories supplying these data: Shell Development Co., Atlantic Refining Co., Socony-Vacuum Oil Co., Inc., Sun Oil Co., Esso Standard Oil Co., and Phillips Petroleum Co.
TABLE 3. Luminous transmittance, T, and chromaticity coordinates $x, y$ of 49 petroleum products

\begin{tabular}{|c|c|c|c|c|c|c|}
\hline \multirow{2}{*}{$\begin{array}{c}\text { Serial } \\
\text { number }\end{array}$} & \multicolumn{2}{|c|}{$\begin{array}{l}\text { ASTM or NPA } \\
\text { color number }\end{array}$} & \multirow{2}{*}{$\begin{array}{c}\text { Laboratory } \\
\text { and sample } \\
\text { number }\end{array}$} & \multicolumn{2}{|c|}{$\begin{array}{l}\text { Chromaticity } \\
\text { coordinates }\end{array}$} & \multirow{2}{*}{$\begin{array}{c}\text { Day- } \\
\text { light } \\
\text { trans } \\
\text { mit- } \\
\text { tance, } \\
T\end{array}$} \\
\hline & $\begin{array}{l}\text { Reported } \\
\text { by refiner }\end{array}$ & $\begin{array}{c}\text { From } \\
\text { nearest } \\
\text { chro- } \\
\text { maticity } \\
\text { match }\end{array}$ & & $x$ & $y$ & \\
\hline 1 & 1 & 0.7 & $\mathrm{C}$ & 0.342 & 0.357 & 0.820 \\
\hline 2 & $1 \mathrm{Dk}$ & .8 & E-6 & .343 & .366 & .848 \\
\hline 3 & $1 / 4$ & .2 & $A-1$ & .317 & .327 & .894 \\
\hline 4 & $1 \mathrm{Dk}$ & .9 & E-1 & .346 & .375 & .866 \\
\hline 5 & 1 & 1.0 & B-1 & .352 & .386 & .847 \\
\hline 6 & $1 \mathrm{Lt}$ & .4 & $\mathrm{E}-7$ & .326 & .344 & .897 \\
\hline 7 & 1 & .8 & $\mathrm{~F}$ & .343 & .365 & .850 \\
\hline 8 & 1 & 1.0 & D-222 & .352 & .379 & .819 \\
\hline 9 & 1 & 1.1 & D-227 & .363 & .392 & .824 \\
\hline 10 & $11 / 2$ & 1.6 & D-228 & .414 & .454 & .735 \\
\hline 11 & $11 / 2$ & 1.5 & $\mathrm{~F}$ & .402 & .445 & .784 \\
\hline 12 & $11 / 2 \mathrm{Dk}$ & 1.6 & E-10 & .418 & .462 & .760 \\
\hline 13 & -.. & 1.1 & $48-54$ & .363 & .397 & .838 \\
\hline 14 & $11 / 4$ & 1.6 & D-218 & .422 & .444 & .634 \\
\hline 15 &.- & 1.5 & A-2 & .404 & .434 & .717 \\
\hline 16 & $11 / 2$ & 1.5 & $\mathrm{C}$ & .407 & .432 & .700 \\
\hline 17 &.-- & 2.1 & $48-56$ & .485 & .477 & .533 \\
\hline 18 & $11 / 2$ & 1.5 & B-2 & .404 & .445 & .782 \\
\hline 19 & $11 / 2$ & 1. 6 & D-223 & .411 & .455 & .741 \\
\hline 20 & $11 / 2$ & 2.0 & A-4 & .466 & .466 & .568 \\
\hline 21 & -.. & 1.5 & $48-55$ & .407 & .448 & .768 \\
\hline 22 & $13 / 4$ & 2.0 & $A-5$ & .482 & .503 & .635 \\
\hline 23 & 2 & 2.0 & F & .474 & .495 & .626 \\
\hline 24 & 2 & 2.2 & D-224 & .491 & .486 & .530 \\
\hline 25 & 2 & 2.2 & D-229 & .487 & .482 & .546 \\
\hline 26 & 2 & 2. 2 & D-219 & .489 & .476 & .429 \\
\hline 27 & $2 \mathrm{Dk}$ & 2. 0 & $\mathrm{E}-4$ & .473 & .496 & .650 \\
\hline 28 & 2 & 1.9 & $\mathrm{C}$ & .464 & .491 & .656 \\
\hline 29 & 2 & 2.1 & B-3 & .479 & .472 & .560 \\
\hline 30 & $21 / 2 \mathrm{Lt}$ & 2.2 & E-8 & .488 & .474 & .518 \\
\hline 31 & $21 / 2$ & 2.6 & $\mathrm{~B}-4 \mathrm{~A}$ & .519 & .468 & .440 \\
\hline 32 & $21 / 2$ & 2.8 & D-230 & .528 & .460 & .392 \\
\hline 33 & $21 / 2$ & 2.5 & B-4 & .513 & .469 & .422 \\
\hline 34 & $21 / 2$ & 3.0 & $\mathrm{~F}$ & .511 & .478 & .508 \\
\hline 35 & $21 / 2$ & 2. 9 & D-225 & .532 & .460 & .367 \\
\hline 36 & $21 / 2 \mathrm{Dk}$ & 2.5 & $\mathrm{E}-11$ & .494 & .456 & .486 \\
\hline 37 & $21 / 2$ & 2.7 & D-220 & .525 & .462 & .310 \\
\hline 38 & $21 / 2$ & 2.7 & $A-6$ & .524 & .465 & .442 \\
\hline 39 & $21 / 2$ & 3.0 & $A-7$ & .538 & .457 & .392 \\
\hline 40 & $23 / 4$ & 3.0 & A-8 & .538 & .456 & .363 \\
\hline 41 & 3 & 3.0 & B-5A & .540 & .452 & .349 \\
\hline 42 & 3 & 3.0 & B-5 & .536 & .457 & .390 \\
\hline 43 & 3 & 3. 2 & D-231 & .550 & .443 & .289 \\
\hline 44 & 3 & 3.3 & D-226 & .553 & .440 & .267 \\
\hline 45 & 3 & 3.5 & D-221 & .561 & .431 & .177 \\
\hline 46 & 3 & 3.0 & $\mathrm{~F}$ & .537 & .457 & .374 \\
\hline 47 & $3 \mathrm{Lt}$ & 2. 7 & E-9 & .521 & .470 & .366 \\
\hline 48 & $31 / 4$ & 4. 0 & A-9 & .592 & .403 & .127 \\
\hline 49 & $31 / 2$ & 3.2 & $\mathrm{E}-12$ & .549 & .444 & .271 \\
\hline
\end{tabular}


finer agrees closely with those indicated by this colorimetric study. However, one oil (Serial No. 48) is graded lower by 0.7 than our measurements would place it, and another similar oil (Serial No. 49) is graded higher by 0.3. This suggests that there is a serious discrepancy between the Union $3 \frac{1}{2}$ glasses used in the two laboratories.

Table 4 gives a breakdown of this sort of difference according to laboratory. It will be noted that there is a remarkably consistent tendency for one laboratory to read high by about 0.2 , for two laboratories to read low by 0.2 and 0.3 , respectively, and for one laboratory to yield agreement with the present results.

\section{Respacing of the Union Color Scale}

By reference to ASTM D 155-45T (see footnote 1 ), it may be seen that the observer views two circular spots of color $(9 / 16$ inch in diameter at a distance of 15 inches) subtending about $2^{\circ}$ at his eye with their centers separated by about $6^{\circ}$, both surrounded by a dark field. The light source (60-watt bulb of about 13 lumens per watt) supplies a luminous flux of 780 lumens nearly all of which, because of the reflector, is fairly uniformly distributed over the hemisphere viewed
TABLE 4. Interlaboratory comparison of grading by the ASTM Union Colorimeter

\begin{tabular}{|c|c|c|c|c|c|c|}
\hline \multirow{2}{*}{$\begin{array}{l}\text { ASTM Union no. } \\
\text { reported by re- } \\
\text { finer }\end{array}$} & \multicolumn{6}{|c|}{$\begin{array}{l}\text { ASTM number reported by the laboratory of the } \\
\text { refiner minus the ASTM number obtained in the } \\
\text { present test }\end{array}$} \\
\hline & Lab. A & Lab. B & Lab. C & Lab. D & Lab. E & Lab. F \\
\hline $1 / 4 \ldots \ldots$ & 0.0 & -...- & $\ldots$ & .... & -... & -... \\
\hline $1 \mathrm{Lt}(=0.8)$ & $\ldots$ & $\ldots$ & $\ldots$ & $\ldots$ & +0.4 & $\ldots$ \\
\hline $1 \ldots \ldots$ & .... & 0.0 & +0.3 & $\begin{array}{r}0.0 \\
-.1\end{array}$ & -... & +0.2 \\
\hline $1 \mathrm{Dk}(=1.2) \ldots$ & 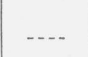 & -... & -..- & -... & $\left\{\begin{array}{l}+.4 \\
+.3\end{array}\right.$ & -..- \\
\hline $11 / 4 \ldots \ldots$ & -.2 & -... & -... & -.1 & $-\cdots$ & 0 \\
\hline $11 / 2 \ldots$ & -.5 & .0 & .0 & $\begin{array}{l}-.1 \\
-.1\end{array}$ & $-\cdots$ & -+- \\
\hline $1 \frac{1}{2} \mathrm{Dk}(=1.7) \ldots$ & -.3 & -..- & -..- & -.2 & +.1 & 0 \\
\hline 2 & $-\ldots$ & -.1 & +.1 & $\begin{array}{l}-.2 \\
-.2\end{array}$ & $-\cdots$ & $-\cdots$ \\
\hline $2 \mathrm{Dk}(=2.2) \ldots$ & $-\cdots$ & $\ldots$ & -..- & -..- & +.2 & $\ldots$ \\
\hline $2 \frac{1}{2} \operatorname{Lt}(=2.3) \ldots$ & & -..- & -... & 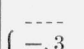 & +.1 & $\cdots$ \\
\hline $21 / 2$ & $\left\{\begin{array}{l}-.2 \\
-.5\end{array}\right.$ & $\begin{array}{r}-.1 \\
.0\end{array}$ & $\cdots$ & $\begin{array}{l}-.3 \\
-.4 \\
-.2\end{array}$ & - n & $\begin{array}{r}.5 \\
--- \\
---\end{array}$ \\
\hline $21 / 2 \mathrm{Dk}(=2.7) \ldots$ & $\ldots$ & $\cdots$ & -... & $\ldots$ & +.2 & $\ldots$ \\
\hline $23 / 4 \ldots$ & -.2 & -... & $-\ldots$ & -... & -..- & ...- \\
\hline $\begin{array}{l}3 \mathrm{Lt}(=2.8) \ldots \\
3 \ldots\end{array}$ & -... & $\left\{\begin{array}{l}.0 \\
.0 \\
.0\end{array}\right.$ & -... & $\left\{\begin{array}{l}-.- \\
-.3 \\
-.5\end{array}\right.$ & $\begin{array}{l}+.1 \\
\cdots-. \\
-. .\end{array}$ & $\begin{array}{r}.0 \\
-.- \\
-.-\end{array}$ \\
\hline $31 / 4 \ldots \ldots$ & -.7 & $\ldots$ & -..- & $\ldots$ & $\ldots$ & $\ldots$ \\
\hline $31 / 2 \ldots \ldots$ & -... & -... & -... & $\cdots$ & +.3 & $-\cdots$ \\
\hline Average...... & -0.3 & 0.0 & +0.1 & -0.2 & +0.2 & -0.1 \\
\hline
\end{tabular}

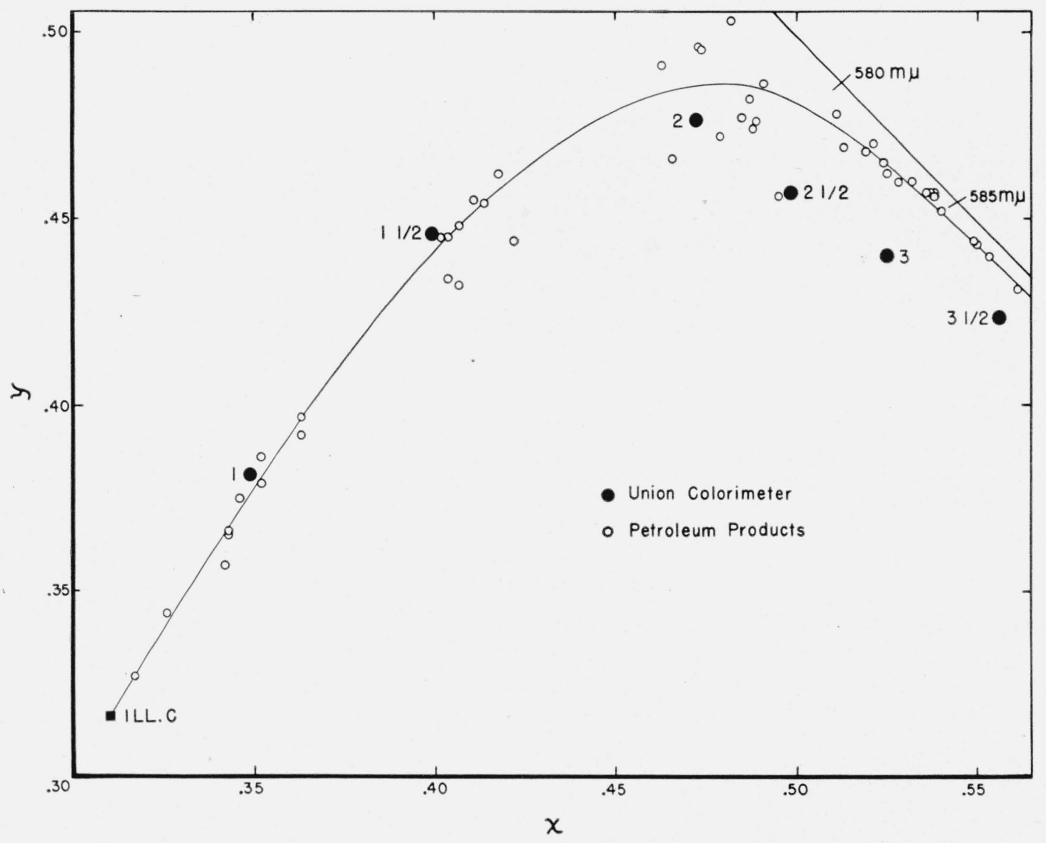

FIGURE 1. Comparison of the chromaticities of the Union colorimeter standards with those of representative petroleum products collected by Subcommittee VI (now Research Division IX), ASTM Committee D-2.

The curved line on this $(c, y)$-chromaticity diagram, running from the point representing illuminant $\mathrm{C}$ (average daylight) to a region near the spectrum locus at $585 \mathrm{~m} \mu$ and beyond, corresponds closely to the average of these petroleum products, and is recommended as a relocation of the Union colorimeter scale. 
toward the opal-glass diffuser, except that there is a bright spot corresponding to the lamp filament located close to the axis of the instrument. The portion of the diffuser viewed in either of the observing fields subtends at a distance of 4 inches about one-twentieth of the hemisphere. The useful light flux striking the diffuser is about 60 lumens. This flux would light up a perfectly transmitting, perfectly diffusing plate to a luminance (photometric brightness) of about 45 foot-Lamberts. Counting the transmittance of the flashed-opal diffuser as 30 percent and the transmittance of the daylight filter as 16 percent, we find the luminance of the field without any oil sample or glass color standard interposed to be about 2 footLamberts. This is about double the least luminance required to permit the eye to detect chromaticity differences with an approach to maximum efficiency; so it may be concluded that the lighting unit is all that could be asked for if used for samples that transmit more than 50 percent (Union No. 2 and lower), but that darker samples would be more easily distinguished in chromaticity if more light were provided.

Consider then three types of spacings of the Union color range: (1) that intended to be uniform for oils of the Union color range viewed in the standard bottles (1 5/16-inch inside diameter) against the sky (as on a shelf in front of a window), (2) that intended to be uniform for the Union colorimeter specified in D $155-45 \mathrm{~T}$, and (3) that intended to be uniform for fields maintained at more than 1 foot-Lambert over the whole range. In all of these scales, set the end points to correspond to a clear glass with standard source C $(r=0.439, g=0.465, b=0.086)$ as zero and to a darkred glass whose chromaticity is represented by the point $(r=0.956, g=0.044, b=0.000)$ at 8.0 , as in Mr. Hancock's suggestion of November 24, 1948 (see table 2). The chromaticity locus to be covered is that corresponding to the average curve drawn on figure 1 of the present report for the 49 representative samples of petroleum products, and the variation of daylight transmittance with chromaticity is based upon the values in tables 3 of the present report, supplemented for the darker parts of the scale by data given by Diller, De Gray, and Wilson (see footnote 6).

The spacing (1), intended to appear uniform if the oils are viewed in bottles against the sky, may be derived with good reliability from the formula for color difference, $\Delta E$, published by Judd ${ }^{10}$ in 1939 and subjected to numerous checks since that time:

$$
\Delta E=600\left[T^{1 / 2} \overline{\Delta S}^{2}+0.02{\overline{\Delta\left(T^{1 / 2}\right.}}^{2}\right],,^{1 / 2}
$$

where $\overline{\Delta S}^{2}=\overline{\Delta r}^{2}+\overline{\Delta g}^{2}+\overline{\Delta b}^{2}, r, g, b$, being chromaticity coordinates on the UCS triangle (see footnote 5), and $T$ being luminous transmittance for standard source C. The factor used to weight the lightness difference relative to the chromatic difference has been taken at 0.02 rather than the published value of 0.04 , because the color produced by the oils in bottles side by side are not juxtaposed but are separated by areas of contrasting color (daylight passing between the bottles). Although this interferes slightly with the perception of chromatic differences, it interferes importantly with the perception of lightness differences. This spacing (1) is of value to the present discussion because, as will appear presently, spacing (2), which it is our purpose to derive, must necessarily lie between spacing (1) and spacing (3).

Spacing (3), intended to appear uniform under the viewing conditions of the Union colorimeter except that the field luminance is to be maintained (such as by a higher wattage source and a system of condensing lenses) in excess of 1 foot-Lambert, can be computed from the analogous formula

$$
\Delta E=600\left[T^{0} \overline{\Delta S}^{2}+0.02{\overline{\Delta\left(T^{1 / 2}\right)}}^{2}\right]^{1 / 2} .
$$

It differs from the formula for spacing (1) by substitution of the term $T^{0}(=1)$, for the term, $T^{1 / 2}$, applying to $\overline{\Delta S}^{2}$. The factor, 0.02 , applies to the Union colorimeter field because here too the color fields are separated by an area of contrasting color (much darker). Because of the low value, 0.02 , of this constant factor, spacing (3) agrees essentially with spacing by uniform chromaticity alone much as was suggested by Mr. Hancock in his letter of November 24, 1948 (see table 2).

Spacings of type (2) intended to yield steps of equal visual importance under the viewing conditions now specified by the Union colorimeter must space out the darker colors (Union Nos. 6, 7, and 8) more than spacing (3) because not enough light is provided to distinguish these dark colors effi-

\footnotetext{
10 D. B. Judd, Specification of color tolerances at the National Bureau of Standards, A m. J. Psychəl. 52, 418 (July 1939).
} 
ciently. The colorimeter field becomes much darker for some samples than the field to which the observer is adapted, in a way similar to viewing dark samples surrounded by the background (sky) supplying the illumination. Since the colorimeter screens the observer's eye from direct light from the source by providing a dark surrounding field, however, spacing (1) based on unshielded viewing must give steps in the dark-color range too large to apply to the Union colorimeter.

Exactly what spacing applies to the conditions of use of the colorimeter might depend importantly on whether room light is customarily excluded from the eyes of the observer, or whether he looks at the colorimeter field for two or three minutes to become adapted to it before making a reading on a dark sample, and on whether he moves the daylight-lamp assembly closer to the opal-glass diffusing plate for dark samples as is permitted by ASTM D 155-45T. Since there is probably no well-defined procedure in these respects, it must be admitted that any scale developed by setting the exponent of $T$ between $\frac{1}{4}$ and $\frac{1}{16}$ would conform essentially to uniform spacing under the range of conditions permitted by ASTM D 155$45 \mathrm{~T}$.

Preliminary study ${ }^{11}$ of the scales resulting from various choices of exponents within this range resulted in the tentative recommendation of the exponent, $\frac{1}{8}$, first, because it corresponds to the best estimate of the conditions under which the ASTM Union colorimeter is used, and second, because it departs by nearly the least amount possible from the present Union colorimeter stand-

${ }^{11}$ Letter, Judd to Hancock, December 23, 1948. ards. No considerations have arisen since this tentative recommendation was made that indicate any change. Accordingly, it is our present recommendation that the respacing of the Union color scale be based upon the formula

$$
\Delta E=600\left[T^{1 / 8} \overline{\Delta S}^{2}+0.02{\overline{\Delta\left(T^{1 / 2}\right)}}^{2}\right]^{1 / 2}
$$

Table 5 shows the specification of 16 points uniformly spaced by formula 2 between the end points $r=0.439, g=0.465, b=0.096$ (standard source C) and $r=0.956, g=0.044, b=0.000$, as in Mr. Hancock's suggestion of November 24, 1948 (see table 2). This scale follows the relocation of the Union locus indicated by the curve drawn in figure 1. The chromaticity coordinates $(x, y)$ for a number of points on this curve were read from figure 1 , and these coordinates were transformed to chromaticity coordinates $(r, g, b)$ on the UCS system (see footnote 5) according to the transformation formulas

$$
\left.\begin{array}{l}
r=\frac{2.7760 x+2.1543 y-0.1192}{-1.0000 x+6.3553 y+1.5405} \\
g=\frac{-2.9446 x+5.0323 y+0.8283}{-1.0000 x+6.3553 y+1.5405} \\
b=1.0000-1.0000 r-1.0000 g
\end{array}\right\} .
$$

These points were plotted in triangular coordinates to form figure 2, and the smooth curve joining them indicates this relocation of the Union color scale in the UCS system. The points on this curve corresponding to uniform spacing by the above formula were found by trial and error by one of us (LP), and table 5 gives the details of the check of this trial-and-error solution showing to what

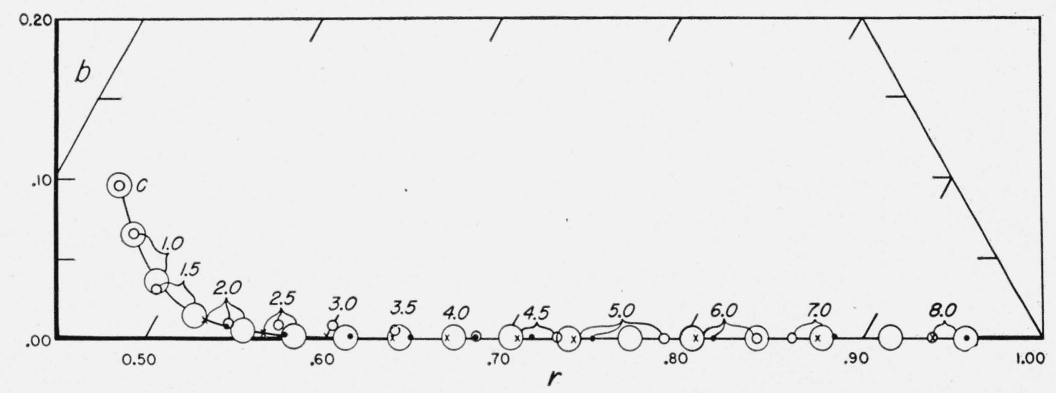

FIGURE 2. Recommended spacing of the Union color scale (large circles) compared with the present Union scale (small circles) and with two suggestions for respacing by H. M. Hancock (dots and crosses).

The UCS chromaticity diagram, formed by plotting at $60^{\circ}$ the $b$-coordinate against the $r$-coordinate, is used. Uniform steps on this diagram are known to correspond, to a good approximation, to chromaticity scales that are perceptually uniform at constant luminance. Note that the darker colors (5 to 8 ) of the recommended spacing are spaced out more than the lighter colors (1 to 4$)$. Note also the good agreement between the recommended scale derived by formula and the two suggestions made_by_Hancock from practical considerations_alone. 
degree the spacing is uniform according to the formula adopted (eq 2). It will be noted that the degree of uniformity indicated by this check cannot be improved unless the chromaticity coordinates are given to four decimals instead of to three. This recommended relocation and respacing of the
Union color scale is compared in figure 2 with the present scale and with Mr. Hancock's two suggestions (see table 2). The open circles defining the chromaticities of the recommended standards have a radius of 0.006 so as to indicate the proposed tolerance.

TABLE 5. Definition of the recommended scale (eq 2), comparison of its daylight transmittance with that of the Union scale, and check of its conformity to the defining equation

\begin{tabular}{|c|c|c|c|c|c|c|c|c|c|c|c|c|c|}
\hline \multirow{3}{*}{$\begin{array}{c}\text { Num- } \\
\text { ber }\end{array}$} & \multicolumn{4}{|c|}{ Definition of scale (2) } & \multirow{3}{*}{$\begin{array}{l}\text { Union } \\
\text { scale, } \\
T_{0}\end{array}$} & \multirow{2}{*}{\multicolumn{8}{|c|}{$\begin{array}{l}\text { Check of the scale (2) against the defining equation: } \\
\qquad \Delta E=600\left[T^{1 / 8} \overline{\Delta S^{2}}+0.02 \overline{\Delta\left(T^{1 / 2}\right)^{2}}\right]^{1 / 2}\end{array}$}} \\
\hline & \multicolumn{3}{|c|}{ Chromaticity coordinates } & \multirow{2}{*}{$\begin{array}{c}\text { Day- } \\
\text { light } \\
\text { trans- } \\
\text { mit- } \\
\text { tance, } \\
T\end{array}$} & & & & & & & & & \\
\hline & $r$ & $g$ & $b$ & & & $T^{1 / 8}$ & $\overline{\Delta r}^{2} \times 10^{4}$ & $\overline{\Delta g}^{2} \times 10^{4}$ & $\overline{\Delta b}^{2} \times 10^{4}$ & $\overline{\Delta S^{2}} \times 10^{4}$ & $T^{1 / 8} \overline{\Delta S}^{2} \times 10^{4}$ & $0.02 \overline{\Delta\left(T^{1 / 2}\right)^{2}}$ & $\begin{array}{c}\text { NBS } \\
\text { units, } \\
\Delta E\end{array}$ \\
\hline 0.0 & 0.439 & 0.465 & 0.096 & 0.922 & ....... & 0.990 & 5. 29 & 0.64 & 9.61 & 15.54 & 15.3 & 0.2 & 24 \\
\hline .5 & .462 & .473 & .065 & .856 & . & .981 & 7. 29 & .04 & 8.41 & 15.74 & 15.3 & .4 & 24 \\
\hline 1. 0 & .489 & .475 & .036 & .774 & 0.751 & .969 & 10.24 & 1. 21 & 4. 41 & 15.86 & 15.2 & .7 & 24 \\
\hline 1.5 & .521 & .464 & .015 & .672 & .654 & .954 & 9.61 & 4.84 & 0.81 & 15.26 & 14.3 & 1.3 & 24 \\
\hline 2.0 & .552 & .442 & .006 & .548 & .443 & .928 & 9.00 & 6.76 & .16 & 15.92 & 14.5 & 1.3 & 24 \\
\hline 2.5 & .582 & .416 & .002 & .436 & .365 & .901 & 8.41 & 7.84 & .01 & 16. 26 & 14.4 & 2.0 & 24 \\
\hline 3.0 & .611 & .388 & .001 & .314 & .287 & .865 & 8.41 & 8.41 & .00 & 16.82 & 14.2 & 1.9 & 24 \\
\hline 3.5 & .640 & .359 & .001 & .215 & .211 & .825 & 9.61 & 9.61 & .00 & 19. 22 & 15.5 & 1.1 & 24 \\
\hline 4.0 & .671 & .328 & .001 & .152 & .096 & .790 & 10.24 & 10. 24 & .00 & 20.48 & 15.9 & .7 & 24 \\
\hline 4. 5 & .703 & .296 & .001 & .109 & .065 & .758 & 10.89 & 10.24 & .01 & 21.14 & 15.7 & .4 & 24 \\
\hline 5.0 & .736 & .264 & .000 & .081 & .036 & .730 & 11.56 & 11.56 & .00 & 23.13 & 16.5 & .4 & 25 \\
\hline 5.5 & .770 & .230 & .000 & .058 & .000 & .700 & 12.25 & 12.25 & .00 & 24.50 & 16.8 & .3 & 25 \\
\hline 6.0 & .805 & .195 & .000 & .040 & .017 & .669 & 12.96 & 12.96 & .00 & 25.92 & 16.9 & .3 & 25 \\
\hline 6.5 & .841 & .159 & .000 & .026 & - . & .634 & 12.96 & 12.96 & .00 & 25.92 & 15.9 & .3 & 24 \\
\hline 7. 0 & .877 & .123 & .000 & .016 & .0066 & .596 & 14.44 & 14.44 & .00 & 28.88 & 16.4 & .3 & 24 \\
\hline 7.5 & .915 & .085 & .000 & .0081 & ........ & .548 & 16.81 & 16.81 & .00 & 33.62 & 17.2 & .3 & 25 \\
\hline 8.0 & .956 & .044 & .000 & .0025 & .0020 & .473 & . & & & & & & \\
\hline
\end{tabular}

It will be noted from figure 2 that the chromaticity spacing of the recommended scale decreases regularly from the dark colors to the light, the total decrease in spacing being by about 50 percent. This decrease in spacing arises primarily from the factor, $T^{1 / 8}$, in the equation defining color difference for the conditions of the ASTM Union colorimeter. The recommended tolerances of \pm 0.006 correspond to about 0.1 step in the respacing of the Union color scale. The relocation of the scale is seen from figure 2 to amount in maximum also to 0.006 in $r, g$, or $b$.

Figure 2 also shows that the recommended scale corresponds within the tolerance of \pm 0.006 either to Mr. Hancock's Chicago suggestion or to his suggestion of November 24, 1948 with the single exception of the No. 2 standard. Since practical considerations led Mr. Hancock to such 
a close correspondence with our best determination of a perfectly uniform scale, it is to be presumed that this recommendation is worthy of adoption by industry.

There remains, of course, the important question of whether industry will become reconciled to any change in definition of the Union scale at all. Perhaps it would avoid confusion if the recommended scale be given a new name and a different number of steps. If such a procedure is decided upon, formula (2) is recommended for use in development of specifications for standard glasses unless an important change in viewing conditions is also made.

\section{Summary}

In response to a request from Subcommittee VI on Color, of ASTM Committee D-2 on Petroleum Products, a study of the colors of typical petroleum products supplied by members of the subcommittee has been carried out, and a relocation and respacing of the Union color scale has been derived from these measurements and from an analysis of the viewing conditions of the ASTM Union colorimeter used in accordance with ASTM D $155-45 \mathrm{~T}$. The recommended colors and tolerances for 17 glass color standards are given in table 6 .
TABLE 6. Recommended color specifications and tolerances for 17 glass color standards comprising a relocation and respacing of the ASTM Union color scale

\begin{tabular}{|c|c|c|c|c|c|}
\hline \multirow[t]{2}{*}{ Number } & \multicolumn{3}{|c|}{$\begin{array}{l}\text { Chromaticity coordinates } \\
\text { (UCS system, footnote 5)a }^{\text {(UCS }}\end{array}$} & \multirow{2}{*}{\multicolumn{2}{|c|}{$\begin{array}{c}\text { Luminous trans- } \\
\text { mittance (ICI } \\
\text { standard source } \\
\text { C) } \\
T\end{array}$}} \\
\hline & $r$ & $g$ & $b$ & & \\
\hline $0.0 \ldots$ & 0.439 & 0.465 & 0.096 & 0.22 & \pm 0.03 \\
\hline $0.5 \ldots$ & .462 & .473 & .065 & .86 & \pm .03 \\
\hline $1.0 \ldots$ & .489 & .475 & .036 & .77 & \pm .03 \\
\hline $1.5 \ldots$ & .521 & .464 & .015 & .67 & \pm .03 \\
\hline $2.0 \ldots$ & .552 & .442 & .006 & .55 & \pm .03 \\
\hline $2.5 \ldots$ & .582 & .416 & .002 & .44 & \pm .02 \\
\hline $3.0 \ldots$ & .611 & .388 & .001 & .31 & \pm .02 \\
\hline $3.5_{\ldots}$ & .640 & .359 & .001 & .22 & \pm .02 \\
\hline $4.0 \ldots$ & .671 & .328 & .001 & .152 & \pm .011 \\
\hline $4.5 \ldots$ & .703 & .296 & .001 & .109 & \pm .008 \\
\hline 5.0 & .736 & .264 & .000 & .081 & \pm .006 \\
\hline $5.5 \ldots$ & .770 & .230 & .000 & .058 & \pm .005 \\
\hline $6.0 \ldots$ & .805 & .195 & .000 & .040 & \pm .004 \\
\hline $6.5 \ldots$ & .841 & .159 & .000 & .026 & \pm .003 \\
\hline $7.0 \ldots$ & .877 & .123 & .000 & .016 & \pm .002 \\
\hline $7.5 \ldots$ & .915 & .085 & .000 & .0081 & \pm .0008 \\
\hline $8.0 \ldots$ & .956 & .044 & .000 & .0025 & \pm .0003 \\
\hline
\end{tabular}

a Tolerances on the chromaticity coordinates $(r, g, b)$ are \pm 0.006 .

Washington, March 15, 1950. 